\title{
ABSTRACTS FROM PAPERS
}

SPINAL INJURIES IN SPORTS: JohN D. LeIDHolt, M.D., F.A.C.S. (I963) (Part of Symposium on the Management of Trauma, University of Colorado), Surg. Clin. N. Amer. 43, 35I.

Injuries to the spine are not common during sporting activities and total about 3 per cent. of all sporting injuries. They appear to have a particularly high mortality if they occur during American football. This may be due to the use of an ill-designed helmet and headguard which accentuates the forces acting on the cervical spine.

The reasons for their relative rarity compared with other injuries in athletes are the mobility of the vertebral segments compared with the rigidity of the long bones and the protection afforded by the trained back muscles of an athlete.

The diagnosis, initial management and treatment of cases with severe spinal cord injuries and also cases with minor fractures and sprains are discussed.

ACUTE SPINAL EPIDURAL ABSCESS $V S$. ACUTE TRANSVERSE MYELOPATHY: P. H. Al trocChi (1963), Arch. Neurol. (Chic.), 9, I7.

A spinal epidural abscess is one of the few treatable causes of paraplegia. However, unfortunately this condition is not infrequently mis-diagnosed, because of its relative rarity and the similarity of its clinical picture, with the more common acute transverse myelopathy. Dr. Altrocchi has analysed the clinical findings in the two conditions over a 25-year period at the Columbia-Presbyterian Medical Centre. There were only eight cases of acute epidural abscess compared with 67 suffering from transverse myelitis. The history and clinical picture were so similar that an immediate laminectomy was not justified. He concludes that X-ray evidence of vertebral osteomyelitis is the most important diagnostic point in favour of epidural abscess, while partial or complete subarachnoidal block should be interpreted with caution as it may also occur in acute transverse myelopathy. Therefore, myelography is recommended to establish the correct diagnosis.

ACUTE TRANSVERSE MYELOPATHY: P. H. Altrocchi (1963), Arch. Neurol. (Chic.), 9, II I.

In this article, the author makes an analysis of the clinical findings in 67 patients suffering from transverse myelitis seen at Columbia-Presbyterian Medical Centre between 1938 and 1962. All these cases had acutely developed intramedullary spinal cord dysfunction, either ascending or static, appearing at any age without any previous history of neurological symptoms. Their ages ranged from I7 months to 65 years. Eleven patients gave a history of preceding upper respiratory infection, 52 per cent. of the cases had fever on admission and 58 per cent. spinal tenderness. The highest level of cord involvement was in the cervical region and two-thirds of the patients were severely paralysed. One-third of the patients made a good recovery, but only one patient recovered completely; two patients died from carcinoma. On lumbar puncture, the manometric studies were normal in 58 cases, but three patients showed evidence of partial block.

In investigating these patients, the author recommends X-ray of the spine and lumbar puncture with careful manometric studies to exclude a possible remediable lesion. If a block is found on lumbar puncture, he recommends a myelogram.

DEVELOPMENT OF USEFUL FUNCTION IN THE SEVERELY PARALYSED HAND: Vernon L. Nickel, M.D., Jacquelin Perry, M.D., \& Alice L. Garrett, M.D., F. Bone Ft. Sury. 45, 933.

The authors are a team from three orthopaedic departments in California, who report on five years' work on about 200 hands of severely paralysed people. Poliomyelitis, miscellaneous neuromuscular disease, quadriplegia, arthritis and other conditions were studied 
and patients' hands fitted with specially designed splints. They used a basic splint, the flexor-hinge splint, either finger- or wrist-driven, cable-driven and artificial-muscledriven splints. A great deal of detailed work was done by them on design, fitting and adjustment of the splints, as well as training of the patients to wear and use them. But 'only a few patients will accept the brace as a permanent device'.

This fact led them to study, develop and refine surgical techniques which, in selected cases, restored isolated function (pinch) to the thumb, fore and middle fingers by an opponens bone block and arthrodesis of the i-p joints of thumb and the neighbouring two fingers and multiple tenodeses.

Some I 20 operations on severely paralysed hands were carried out, presumably mainly on hands disabled by poliomyelitis. No indication is given of the numbers of hands of quadriplegics, hemiplegics and patients with plexus-paralysis on whom they operated. This, however, would seem essential if we are to assess the value of these procedures for conditions other than lower motor neuron lesions. Their statement that 'in a large measure management of upper extremity paralysis is the same regardless of the cause' can hardly be accepted by workers in this field familiar with the neuro-physiological differences between cerebral, spinal cord and peripheral paralysis of the limbs.

ACUTE TUBULAR NECROSIS AND ITS MANAGEMENT: JOSEPH H. Holmes, M.D., D.Med.Sc. (1963) (Part of Symposium on the Management of Trauma, University of Colorado), Surg. Clin. N. Amer. 43, 555.

The author describes the management of $\mathrm{I}$ Io patients with acute renal failure requiring dialysis. Renal failure followed surgery in 48.5 per cent. and trauma in 12.5 per cent., of these patients 75 per cent. had suffered from shock and 12.5 per cent. from transfusion reactions.

Conservative management is described including use of a weighing bed, measurements of serum and urinary electrolytes and osmolality to help control water and electrolyte balance. The marked reduction in salivary flow in patients with uraemia and restricted fluids is described; under these conditions the use of chewing gum helps to prevent oral complications such as parotitis. Hyperkalaemia was controlled with insulin and glucose, sodium bicarbonate and ion exchange resins.

In 58 patients treated by dialysis from 1953 to 1958 the mortality was 53 per cent. and in 52 patients treated from 1959 to 1962 the mortality was 22 per cent. The author attributes this improvement to (I) earlier and more frequent dialysis, (2) improved dialysis technique and (3) earlier transfer of patients to dialysis centre. The authors current indications for dialysis include progressive hyperkalaemia especially if causing ECG changes, falling $\mathrm{CO}_{2}$ combining power to $12 \mathrm{mEq}$./1. or less, rapidly rising blood urea especially in post-traumatic cases, excessive fluid retention, and clinical signs of progressive uraemia. Dialysis is indicated during the early diuretic phase if signs of uraemia occur.

With the development of regional heparinisation, it has become practical to dialyses patients within a few days of severe multiple injuries. Although this paper is not concerned with paraplegics, acute renal failure can complicate traumatic paraplegia particularly when there are associated injuries and a prolonged period of shock; as the patients' lives can often be saved by appropriate treatment, all clinicians having care of such patients must now be familiar with the recognition and management of acute renal failure. This paper gives a concise and easily understood account of the problem. Although all the references are to the American literature the views expressed will find general acceptance in this country.

AN EXPERIMENTAL STUDY OF THE TREATMENT OF THE NEUROGENIC BLADDER: Bradley, Wittmers, \& Chou (1963), Amer. F. Urol. 90, 5.

Bradley, Wittmers and Chou have conducted a number of animal experiments with the object of securing evacuation of the neurogenic bladder by means of electrical stimulation 
of an electrode embedded in the bladder wall. Many difficulties were encountered owing to the paraplegia, but in some dogs it was possible to produce complete evacuation of the bladder without reflux four-hourly as a result of stimulation.

In some instances tonic contraction of the legs developed during stimulation and there was some evidence that the stimulus also caused pain in the cauda equina group of dogs.

The authors suggest that the use of an indwelling catheter may diminish the excitability of the bladder to stimulation. They state that they have also used the method with a group of patients but give no information on this aspect.

TRENDS IN THE MANAGEMENT OF URETHRAL COMPLICATIONS IN PARAPLEGICS: Steve J. Misak, \& R. Carl Bunts (I963), Amer.F. Urol. 9o, 3.

These authors point out that there has been a steady decline in the incidence of urethral complications in paraplegics, this decline being due to a number of factors. These factors include the avoid ance of incontinence clamps, of pressure sores from urinals, poor perineal hygiene and severe adductor spasms. They rightly emphasise that the major factor is the exercise of scrupulous care and gentleness in passing catheters, which should be of small calibre.

They prefer continuous to intermittent drainage. The authors further advise their patients to irrigate the bladder three times a day after their return home, advice which would not be acceptable to all authorities.

PERPETUATION OF INFECTION IN UNOBSTRUCTED URINARY TRACTS BY VESICO-URETERAL REFLUX: J. A. Hutch, E. R. Miller, \& Frank Herman Jr. (1963). Amer. F. Urol.

These authors studied 400 patients with recurrence of chronic urinary infection by means of cine-photography during micturition. Many of these patients had no evidence of obstruction but nearly half had demonstrable ureteric reflux. They concluded that the basic defect was, therefore, incompetence of the uretero-vesical valve, the sequence of events being:

(a) Primary incompetence of the uretero-vesical valve leading to reflux.

(b) Infection of the bladder via the urethra.

CAUSE AND CORRECTION OF URETERAL REFLUX: L. W. HOOVERTON, \& R. LICH Jr. (1963). Amer. F. Urol.

These authors emphasise the fact that vesical infection is responsible for vesico-ureteric reflux, and regard obstruction as a secondary factor. They advise control of infection to reverse the process from moderate to mild reflux and to prevent deterioration of renal function. A few more advanced cases may be suitable for reconstructive measures, but those with evidence of gross renal damage require diversion of the urine.

\section{BOOK REVIEW}

MARGIN OF SAFETY: JOHN ROWAN WILSON (1963). (256 pp., Illustrated, 2is.) London: Collins.

Until the last decade, poliomyelitis was an important cause of death and deformity. The doctors who have treated this condition have concentrated their efforts on the development of respiratory units to deal with the acute cases in whom the respiratory muscles have been involved and on the prevention and the correction of deformities in the later stages.

This book describes the background and wider implications of the last stages of the conquest of poliomyelitis-one of the great triumphs in medicine. Epidemic polio 
attacked modern society in the last 50 years, and its conquest by that society is a fascinating demonstration of the power of modern science and technology.

The virtual elimination of this disorder has been due to the fundamental research work of doctors and scientists far removed from the clinical field. The first and probably most important step was taken by Enders (1949) when he succeeded in growing the Lansing strain of the virus in human embryonic tissue. Once the virus had been grown, Salk was able to produce a vaccine of the killed virus, which after some initial setbacks became the standard form of prophylaxis in the United States of America.

This vaccine did not provide the whole answer to the problem since the immunity produced was not permanent and did not develop quickly enough to deal with an epidemic in a non-vaccinated population.

The present definitive therapy appears to be the use of the attenuated live virus developed by Sabin in the United States of America and given its clinical trials in the United Soviet Socialist Republic, where 77 million have received the vaccine.

The development of this work is of great interest from an historical point of view to any doctor who is concerned with the treatment of paralysed patients. The whole subject, with its political and social background, is critically examined and most entertainingly dealt with by the author who is deputy Editor of the B.M.F. and participated, in his former capacity as Medical Director of one of the largest American pharmaceutical firms, in helping to organise several of the live poliomyelitis vaccine trials. 